\title{
Loss of IL-7Ra is Associated With CD4+ T Cell Depletion, High IL-7 Levels and CD28 Down-regulation in HIV Infected Patients Bence Rethi* ${ }^{* 1}$, Caroline Fluur ${ }^{1}$, Ann Atlas ${ }^{2}$, Sven Grützmeier ${ }^{3}$, Angelo De Milito ${ }^{1}$, Éva Rajnavölgyi ${ }^{4}$ and Francesca Chiodi ${ }^{1}$
}

\author{
Address: ${ }^{1}$ Microbiology and Tumor Biology Center, Karolinska Institutet, Stockholm, Sweden, ${ }^{2}$ Infectious Diseases Unit, Karolinska University \\ Hospital, Solna, Sweden, ${ }^{3}$ Gay Men's Health Clinic, The Soder Hospital, Stockholm, Sweden and ${ }^{4}$ Institute of Immunology, University of \\ Debrecen, Hungary \\ Email: Bence Rethi* - Bence.Rethi@mtc.ki.se \\ * Corresponding author $¥$ Presenting author
}

from 2005 International Meeting of The Institute of Human Virology

Baltimore, USA, 29 August - 2 September 2005

Published: 8 December 2005

Retrovirology 2005, 2(SuppI I):P84 doi: 10.1 I86/1742-4690-2-SI-P84

Interleukin-7 (IL-7) is a survival factor for naïve and memory $\mathrm{T}$ lymphocytes and it also increases $\mathrm{T}$ cell proliferation during lymphopenic conditions. Elevated levels of IL-7 have been found in the blood of HIV+ patients, which was considered as a homeostatic response to peripheral $\mathrm{T}$ cell depletion.

We showed that HIV infection is associated with an increased proportion of IL-7Ra low/negative peripheral T lymphocytes. Down-regulation of IL-7 R $\alpha$ on T cells was correlated with the depletion of $\mathrm{CD} 4+\mathrm{T}$ cells and also with the increased concentration of serum IL-7. The decreased IL-7R $\alpha$ expression resulted in the reduced survival capacity of T cells in presence of IL-7 and was associated with low $\mathrm{Bcl}-2$ expression. Mostly the memory T cells down-regulated the IL-7R $\alpha$ and we found a strong association between $\mathrm{CD} 28$ and IL-7R $\alpha$ down-regulation. Accordingly, only CD28+ T cells responded to IL-7 with strong Bcl-2 upregulation.

The positive effects of IL-7 on survival and homeostatic proliferation of T cells might be severely impaired in HIVinfected individuals due to the decreased IL-7R $\alpha$ expression. Chronic T cell activation may lead to an overall decrease of IL-7 mediated survival signals in HIV-infected individuals. 